\title{
ORDENANDO REDES E ORGANIZANDO BAGAGENS: PROPOSTA DE LAYOUT PARA EMBARCAÇÕES REGIONAIS DA AMAZÔNIA
}

Fábio Henrique Dias Máximo

Universidade Federal do Amazonas

fabiomaximo@ufam.edu.br

Tiago Alfaia da Silva

Universidade Federal do Amazonas

tiago_alfaia@yahoo.com.br

Resumo: As embarcações mistas realizam o transporte de cargas e passageiros durante viagens intermunicipais pelo o Amazonas. No cenário atual apresentam problemas estruturais e organizacionais que interferem na circulação e acessibilidade do passageiro. Assim sendo, o trabalho tem objetivo de apresentar o desenvolvimento de layout organizacional para acomodação de passageiros no convés das embarcações mistas. Para isso adotou-se metodologia baseada em Moraes e Mont'Alvão (2003) que consiste na realização da apreciação e diagnose onde se realizou observações assistemáticas, registros cursivos contínuos e aplicação da tabela GUT. Ao gerar a diagnose e as recomendações ergonômicas, algumas propostas de configurações de layout foram elaboradas e submetidas a técnica de avaliação binária de critérios ponderados. Concluímos que a configuração de um novo layout, levando em consideração todas as recomendações geradas nesta pesquisa, proporciona ordenação e organização das redes e bagagens, conferindo melhor acessibilidade e circulação dos passageiros no convés.

Palavras-chave: Ergonomia; Embarcação regional; Acomodação de passageiros.

Abstract: Regional vessels perform the transportation of cargo and passengers during commuting by Amazon. In the present scenario have structural problems that interfere at circulation and accessibility of the passenger. Thus, the study aimed to present the development of organizational layout for passenger accommodation on the deck of mixed vessels. For this, the methodology have based on Moraes and Mont'Alvão (2003) which consists in carrying out the assessment and forecast which made unsystematic observations, continuous cursive records and application of GUT table. When generating the diagnosis and ergonomic recommendations, some proposals layout settings have been prepared and submitted the binary evaluation technique of weighted criteria.

Keywords: Ergonomics; Regional vessel, Passenger accommodation 


\section{INTRODUÇÃO}

A região amazônica possui um sistema de transporte para interligação dos municípios um tanto diferenciado, em relação às outras regiões do Brasil dado que "existe uma Amazônia que ainda segue o padrão rio-várzea, onde o transporte pela via fluvial para a maior parte das localidades é a única alternativa, pois ainda habitadas por populações caboclas que têm no rio uma de suas fontes principais de vida" (NOGUEIRA Apud FROTA, 2006). Tanto que o meio de transporte intermunicipal é realizado por meio de embarcações regionais.

Por esta razão, esta pesquisa realizou o estudo ergonômico do convés da embarcação regional mista, relacionado à atividade de acomodação dos passageiros. 0 objetivo foi desenvolver um layout organizacional adequado tanto para acomodação das bagagens quanto acomodação dos passageiros no convés sem comprometimento do direto de ir e vir no convés da embarcação.

Para desenvolver o layout, primeiramente, fez-se um levantamento de dados por meio de pesquisa bibliográfica e eletrônica, com a finalidade de identificar parâmetros que pudessem ser utilizados. Em seguida, houve a apreciação ergonômica, na qual foram identificados e delimitados os problemas no convés. Após a categorização desses problemas utilizou-se a diagnose ergonômica para realização da análise da ambiência da tarefa, análise da tarefa do passageiro chegando-se ao diagnóstico ergonômico, onde se elaborou um quadro com recomendações para diminuição dos constrangimentos na tarefa dos passageiros durante sua acomodação.

Logo, os resultados deste levantamento definiram os requisitos e parâmetros de projeto, fundamentais para processo de geração de alternativas de layouts. Em seguida esta mesma base de dados foi utilizada para fundamentar o método de escolha da alternativa mais viável para a realidade do transporte fluvial de passageiros da região.

\section{DESENVOLVIMENTO}

\subsection{0 convés do problema}

Durante visitas técnicas às embarcações, observações assistemáticas foram feitas para identificar problemas no convés. Os problemas foram categorizados de acordo com classificação taxionômica proposta por Moraes e Mont'Alvão (2003), de modo que os principais problemas foram: informacional/visual, de acessibilidade, espacial/arquitetural de interiores e acidentários.

Para a priorização e consolidação dos problemas, utilizou-se a técnica da tabela GUT (Gravidade, Urgência, Tendência) proposta por Kepner e Tregoe Apud Moraes e Mont'Alvão (2003). Para criação da tabela, 27 passageiros foram consultados, de modo que os problemas foram analisados e pontuados de acordo com escala de valores que variam do número 1 (um) ao número 5 (cinco) conforme visto no Quadro 1. 
Quadro 1 - Escala de valores

\begin{tabular}{|llll|}
\hline VALOR & GRAVIDADE & URGÊNCIA & TENDÊNCIA \\
\hline $\mathbf{5}$ & $\begin{array}{l}\text { Prejuízos e/ou } \\
\text { dificuldades são graves }\end{array}$ & $\begin{array}{l}\text { Necessária ação } \\
\text { imediata }\end{array}$ & $\begin{array}{l}\text { Se nada for feito a situação irá } \\
\text { piorar rapidamente }\end{array}$ \\
\hline $\mathbf{4}$ & Muito grave & Alguma urgência & Vai piorar em pouco tempo \\
\hline $\mathbf{3}$ & Grave & O mais cedo possível & Vai piorar em médio prazo \\
\hline $\mathbf{2}$ & Pouco grave & Pode esperar um pouco & Vai piorar, mas em longo prazo. \\
\hline $\mathbf{1}$ & Sem gravidade & Não tem pressa & Não vai piorar e pode melhorar \\
\hline
\end{tabular}

Fonte: Adaptado de Mores e Mont'Alvão, 2003.

E com base nos números mais recorrentes dados a gravidade; urgência e; tendência, dos 27 passageiros, multiplicaram-se os valores resultando na ordem dos problemas que causam maiores constrangimentos aos passageiros (Tabela 1).

Tabela 1-Tabela GUT

\begin{tabular}{lllll}
\hline PROBLEMAS & GRAVIDADE & URGÊNCIA & TENDÊNCIA & G X U \\
\hline Informacionais & 1 & 1 & 1 & $1\left(4^{\circ}\right)$ \\
\hline Acessibilidade & 3 & 3 & 1 & $9\left(1^{\circ}\right)$ \\
\hline Espaciais & 3 & 2 & 1 & $6\left(2^{\circ}\right)$ \\
\hline Acidentários & 2 & 2 & 1 & $4\left(3^{\circ}\right)$ \\
\hline
\end{tabular}

Fonte: Elaborado pelo autor, 2014, com base na pesquisa realizada.

\subsection{Análise da ambiência}

De acordo com as observações em campo e a medição de 9 (nove) embarcações, elaborou-se a planta baixa da área do convés mostrando os equipamentos e partes estruturais onde os passageiros eram acomodados. Verificouque o arranjo das redes dependia da dimensão da embarcação. Haviam embarcações, de 21,60 m a 27,40 m de comprimento, que as redes são dispostas em duas fileiras ao longo do convés (Figura 1), e embarcações, com comprimento entre 29 m e 32 m, que as redes são dispostas em três fileiras ao longo do convés (Figura 2).

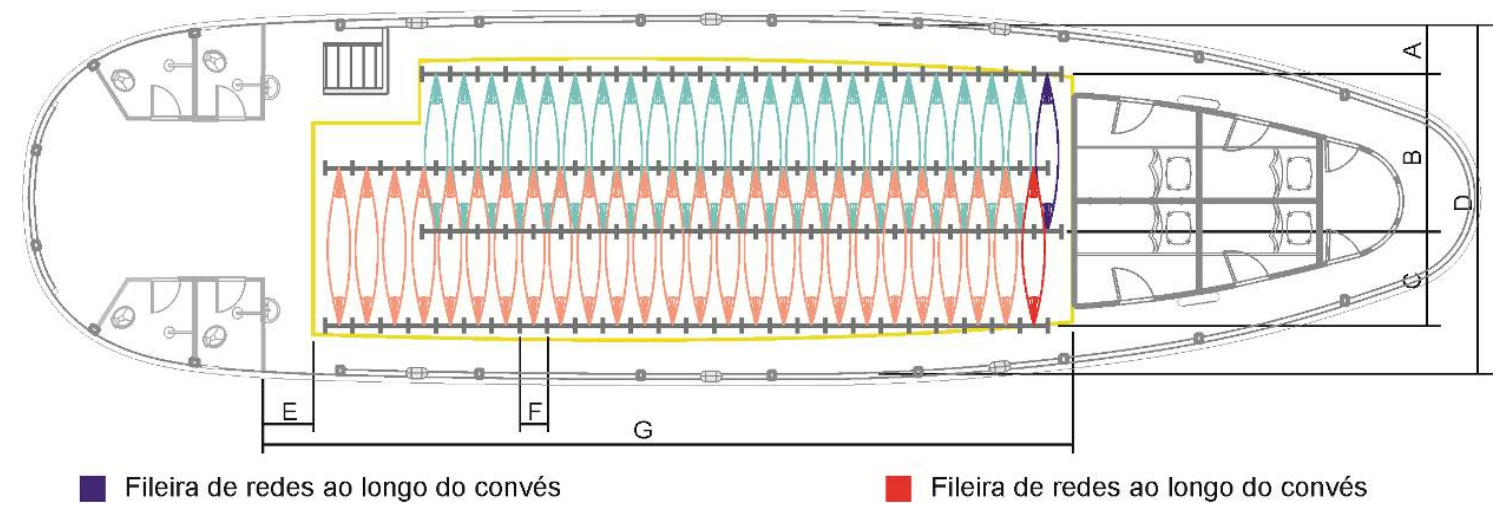

Figura 1 - Arranjos das redes da embarcação com comprimento de 21,60 m - 27,40 m.

Fonte: Elaborado pelo autor, 2014, com base na pesquisa realizada. 


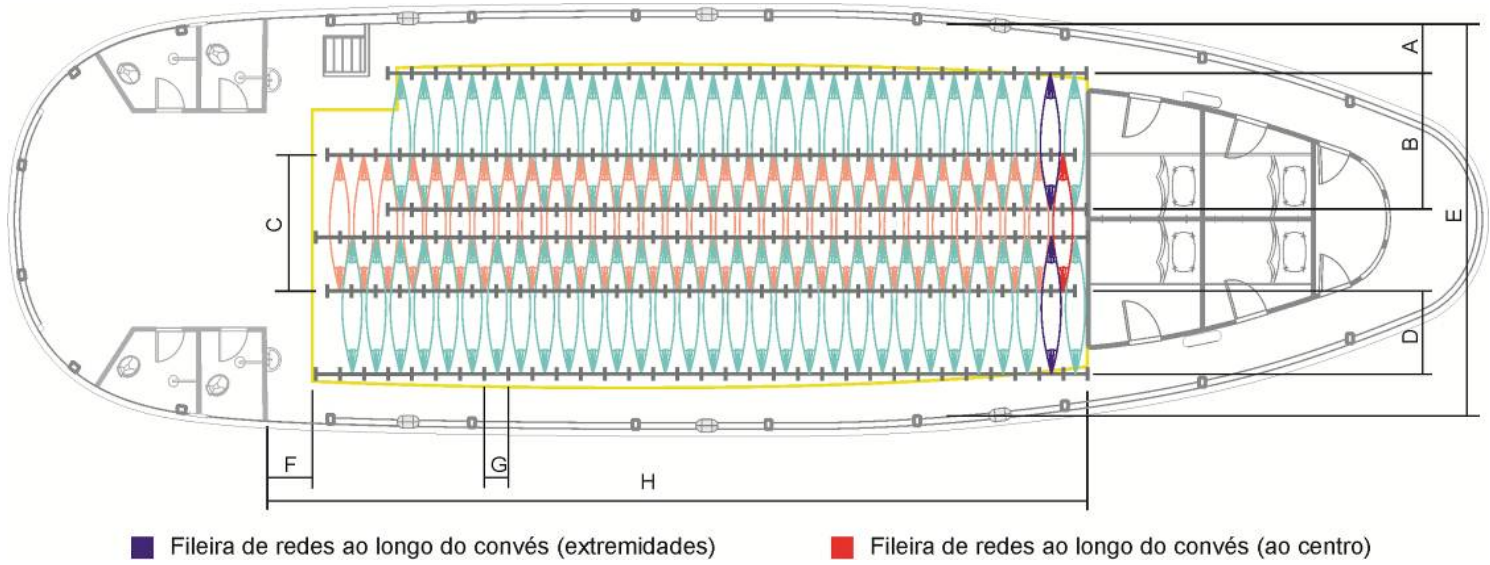

Figura 2 - Arranjos das redes da embarcação com comprimento de 29 m - 32 m.

Fonte: Elaborado pelo autor, 2014, com base na pesquisa realizada.

\subsection{Análise da tarefa do passageiro e diagnóstico}

A partir de observações da tarefa do passageiro, elaborou-se fluxograma (Figura 3), assim como o registro das atividades (Quadro 2) referente à acomodação do passageiro, permitindo a visualização da sequência de todas as etapas percorridas durante o embarque.

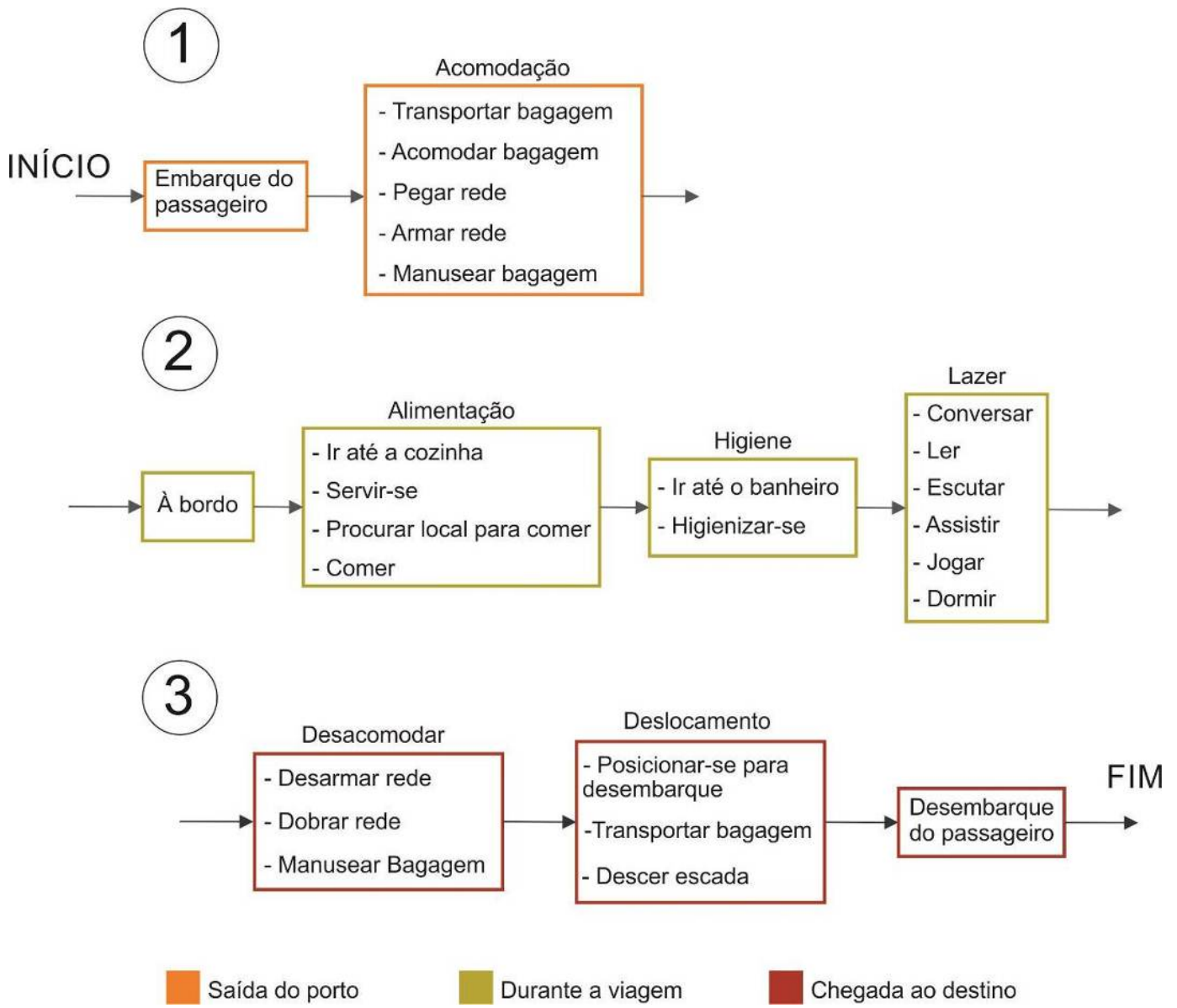

Figura 3 - Fluxograma das atividades da tarefa

Fonte: Elaborado pelo autor, 2014, com base na pesquisa realizada. 
Quadro 2 - Acomodação do passageiro

a) Transportar bagagem

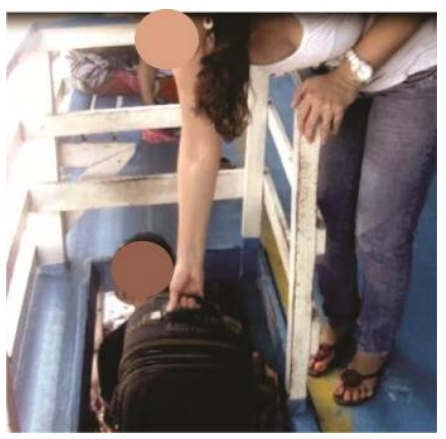

c) Pegar rede

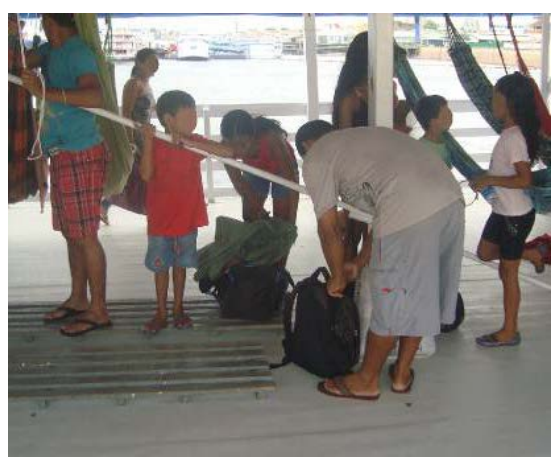

e) Manusear bagagem

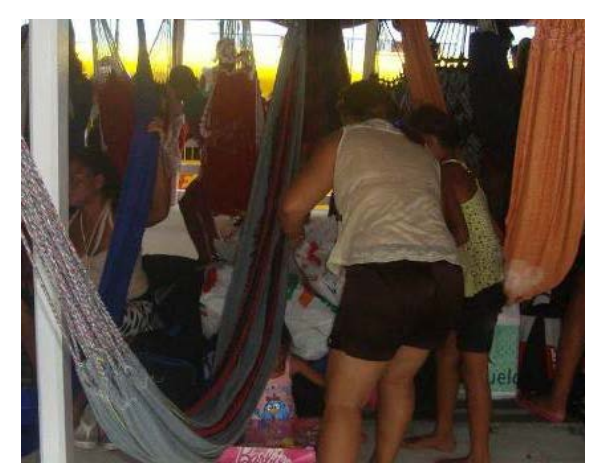

b) Procurar local disponível

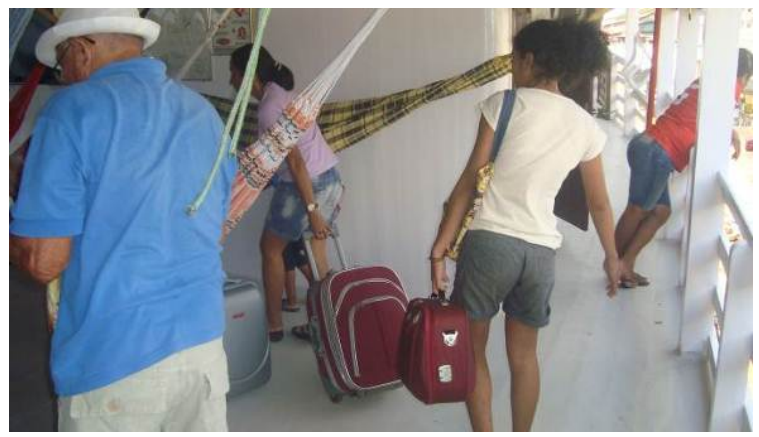

d) Armar rede

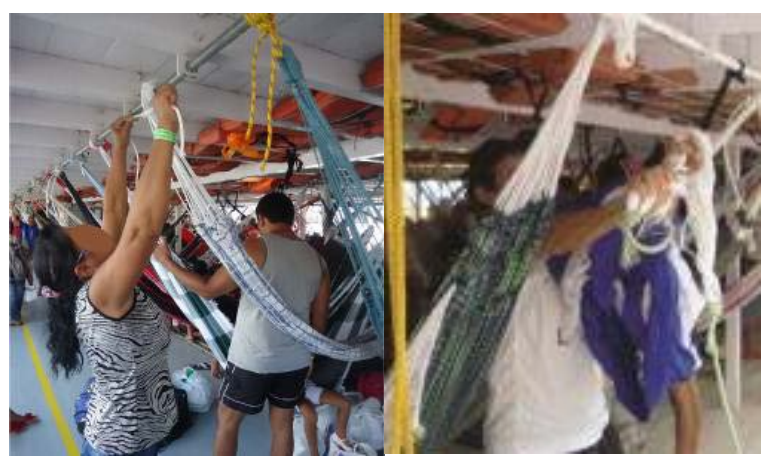

f) Deitar-se

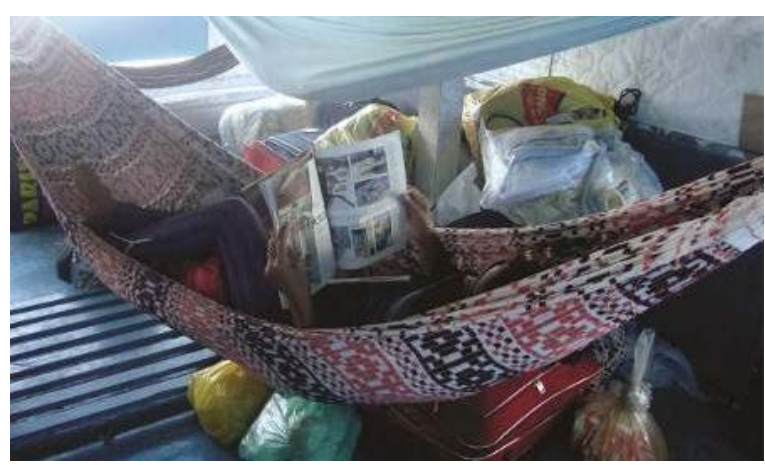

Fonte: Elaborado pelo autor, 2014, com base na pesquisa realizada.

Com base nas análises, foi diagnosticado o problema. Algumas recomendações para diminuição dos constrangimentos da tarefa do passageiro foram elaboradas e organizadas de acordo com o Quadro 3. 
Quadro 3 - Diagnóstico ergonômico

\begin{tabular}{|c|c|c|c|c|}
\hline $\begin{array}{l}\text { CLASSE DE } \\
\text { PROBLEMAS }\end{array}$ & PROBLEMAS & $\begin{array}{l}\text { EXIGÊNCIAS E } \\
\text { CONSTRANGIMENTOS }\end{array}$ & $\begin{array}{l}\text { AVALIAÇÕES E } \\
\text { OPINIÕES }\end{array}$ & RECOMENDAÇÕES \\
\hline $\begin{array}{l}\text { Informacional: } \\
\text { Local de } \\
\text { instalação das } \\
\text { redes }\end{array}$ & $\begin{array}{l}\text { Instalação } \\
\text { das redes } \\
\text { em local } \\
\text { inadequado }\end{array}$ & $\begin{array}{l}\text { O passageiro instala } \\
\text { sua rede em } \\
\text { qualquer área livre } \\
\text { ocupando espaços } \\
\text { inadequados. }\end{array}$ & $\begin{array}{l}\text { Suporte para } \\
\text { instalação das redes } \\
\text { não possui } \\
\text { sinalização que } \\
\text { indique a área a ser } \\
\text { ocupada. }\end{array}$ & $\begin{array}{l}\text { Aplicar sinalização } \\
\text { que indique e } \\
\text { instrua local } \\
\text { adequado para } \\
\text { armar rede; } \\
\text { Delimitar área a ser } \\
\text { ocupada no suporte } \\
\text { de instalação. }\end{array}$ \\
\hline $\begin{array}{l}\text { Acessibilidade: } \\
\text { Rede }\end{array}$ & $\begin{array}{l}\text { Dificuldade } \\
\text { para entrar } \\
\text { e sair da } \\
\text { rede. }\end{array}$ & $\begin{array}{l}\text { O passageiro } \\
\text { assume posições } \\
\text { desconfortáveis, } \\
\text { precisa desviar das } \\
\text { bagagens no chão. }\end{array}$ & $\begin{array}{l}\text { Pequeno espaço } \\
\text { entre redes; } \\
\text { Caminhos de acesso } \\
\text { obstruídos por } \\
\text { bagagens dos } \\
\text { usuários. }\end{array}$ & $\begin{array}{l}\text { Aumentar espaço } \\
\text { entre redes; } \\
\text { Possibilitar acesso } \\
\text { do passageiro na } \\
\text { rede; Retirar } \\
\text { bagagens do } \\
\text { caminho. }\end{array}$ \\
\hline $\begin{array}{l}\text { Acessibilidade: } \\
\text { Bagagens }\end{array}$ & $\begin{array}{l}\text { Dificuldade } \\
\text { de manusear } \\
\text { a bagagem. }\end{array}$ & $\begin{array}{l}\text { O passageiro se } \\
\text { abaixa para retirar } \\
\text { bagagens de cima } \\
\text { das outras, para } \\
\text { retirar e repor } \\
\text { material. } \\
\end{array}$ & $\begin{array}{l}\text { O passageiro } \\
\text { assume posições } \\
\text { desconfortáveis } \\
\text { durante o manuseio } \\
\text { da bagagem. }\end{array}$ & $\begin{array}{l}\text { Utilização de } \\
\text { suportes para as } \\
\text { bagagens de modo } \\
\text { a separar bagagem } \\
\text { de mão dos outros } \\
\text { tipos de bagagens. }\end{array}$ \\
\hline $\begin{array}{l}\text { Espacial: } \\
\text { Corredores }\end{array}$ & $\begin{array}{l}\text { Obstrução } \\
\text { dos } \\
\text { corredores }\end{array}$ & $\begin{array}{l}\text { O passageiro precisa } \\
\text { inclinar-se e desviar } \\
\text { das redes no } \\
\text { corredor. }\end{array}$ & $\begin{array}{l}\text { Corredores } \\
\text { obstruídos por } \\
\text { redes, bancos ou } \\
\text { cadeiras. }\end{array}$ & $\begin{array}{l}\text { Os corredores } \\
\text { devem estar } \\
\text { desobstruídos e } \\
\text { com largura mínima } \\
\text { de } 80 \mathrm{~cm} \text {; }\end{array}$ \\
\hline
\end{tabular}

Fonte: Elaborado pelo autor, 2014, com base na pesquisa realizada.

\section{CONCLUSÃO}

Tendo em vista todos os aspectos levantados e o diagnóstico gerado pela pesquisa, fez-se necessário a geração de alternativas layout que simulassem como a implementação do estudo pode se configura em uma proposta viável.

Para tanto, foram demonstrados dois conceitos. Conceito um: a acomodação dos passageiros é segregada em ambiente no convés, adaptando um módulo com cama; bagageiro e mesa de jantar. Conceito dois: a acomodação dos passageiros seria em agrupamento de rede e bagageiro, mantendo relação modular neste conjunto.

\subsection{Propostas conceito 01}

A Figura 5 propõe que acomodação do passageiro pode ser feita em beliches e o local para as bagagens fica embutido abaixo do beliche. Proporciona mais conforto ao passageiro, havendo poltronas tanto para descanso quanto para arranjos que possibilitem atividades de entretenimento viagem. Já na Figura 6, há uma área delimitada por três divisórias posicionadas a $60^{\circ}$ umas das outras. Resultando em três acesso ao local de acomodação aproveitando o espaço do convés. A Figura 7 consiste numa área delimitada por duas divisórias perpendiculares, o passageiro fica acomodado em beliches e o local para as bagagens fica embutido abaixo da cama inferior. Com adequação da mesa de centro essa alternativa visa oferecer comodidade e bem-estar ao passageiro permitindo-o fazer refeição no local de acomodação 

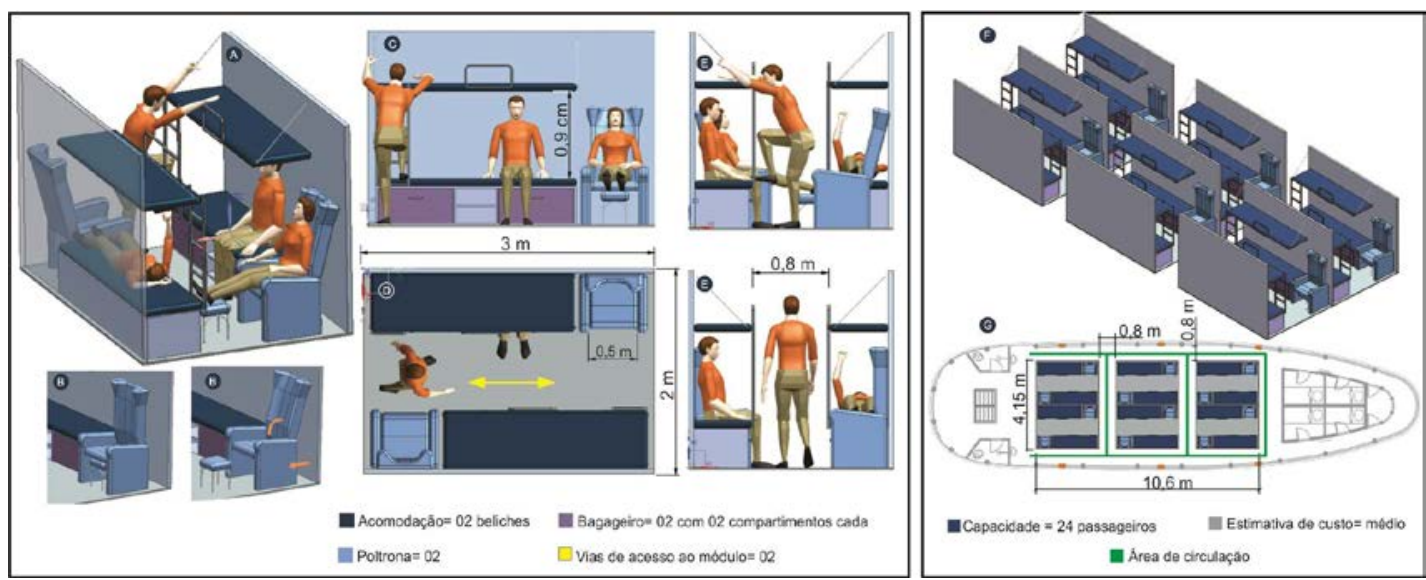

Figura 5 - Módulo (esq.); Layout proposto (dir.): Vista em perspectiva (F), visualização planta baixa (G) Fonte: Elaborado pelo autor, com base na pesquisa realizada.
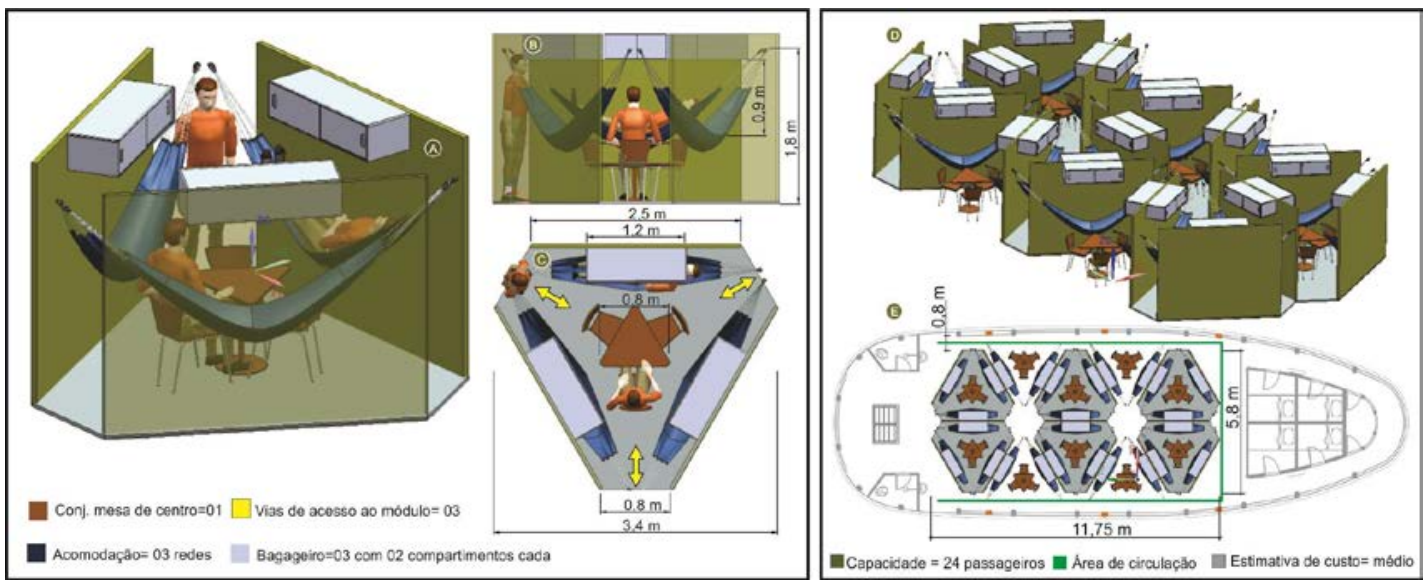

Figura 6 - Módulo (esq); Layout proposto (dir.)

Fonte: Elaborado pelo autor, com base na pesquisa realizada.
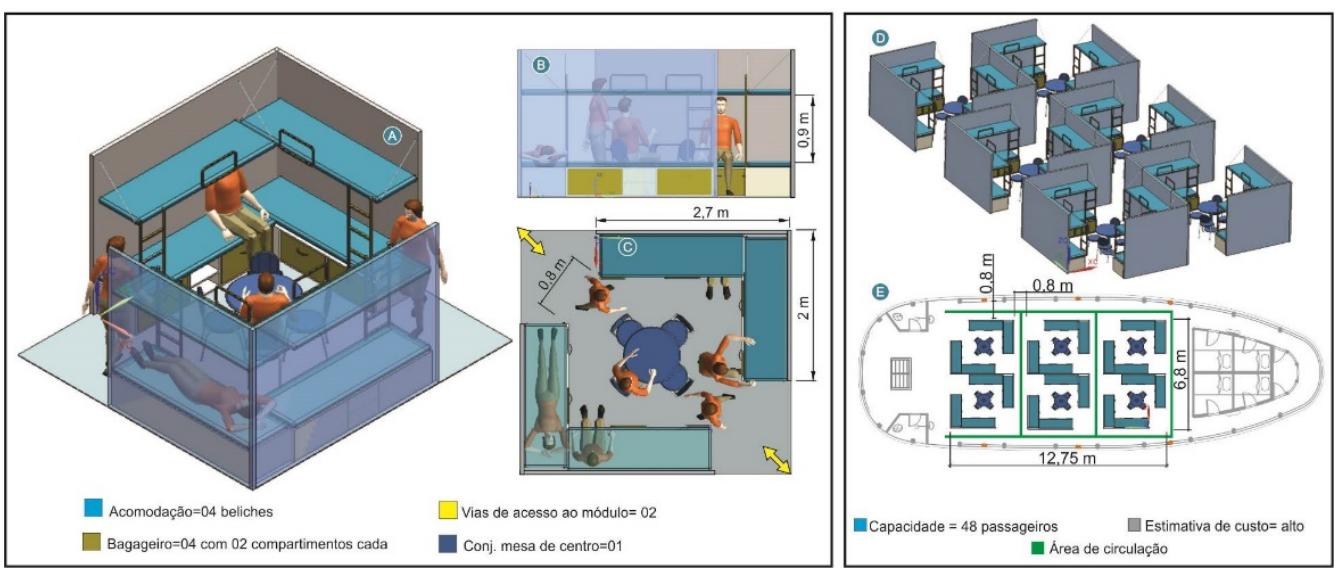

Figura 7 - Módulo (esq.); Layout proposto (dir.).

Fonte: Elaborado pelo autor, com base na pesquisa realizada.

\subsection{Propostas conceito 02}

A Figura 8 demonstra a instalação de redes num suporte formando arranjos circulares, comportando o bagageiro ao centro, aumentando a área de acomodação. Assim, há maior espaço entre as redes facilitando acesso. Já na Figura 9, no entanto com três redes, fixadas a um suporte, umas ao lado das outras, o bagageiro se 
posiciona na extremidade da rede, sendo utilizado com múltipla função, guardar bagagem e servir como banco.

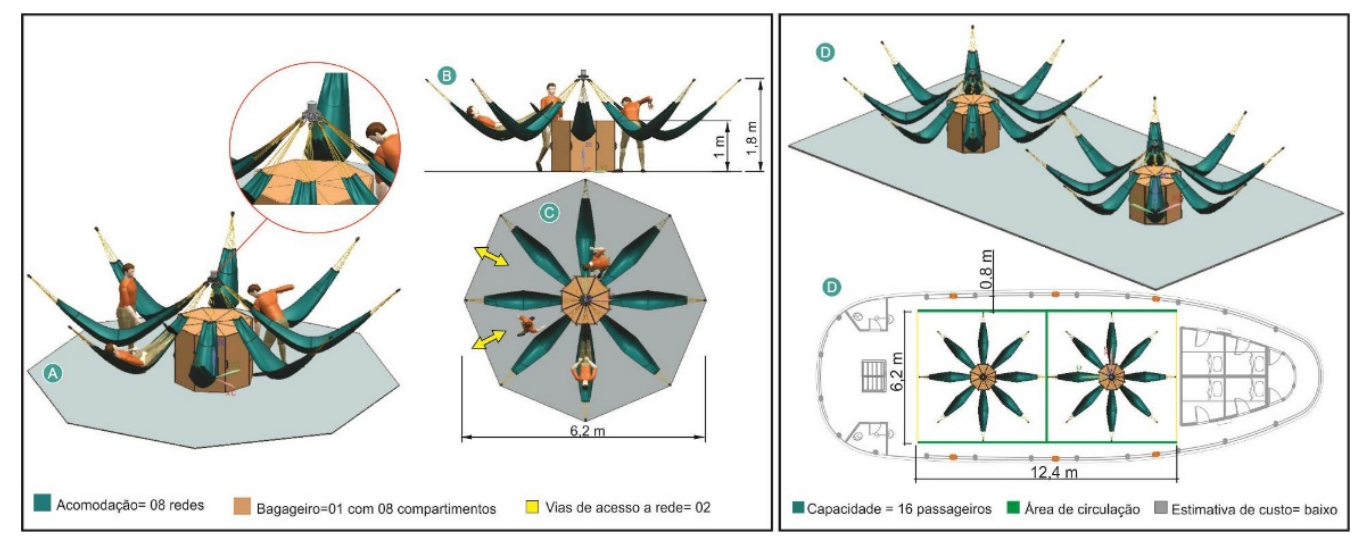

Figura 8 - Módulo (esq.); Layout proposto (dir.)

Fonte: Elaborado pelo autor, com base na pesquisa realizada.
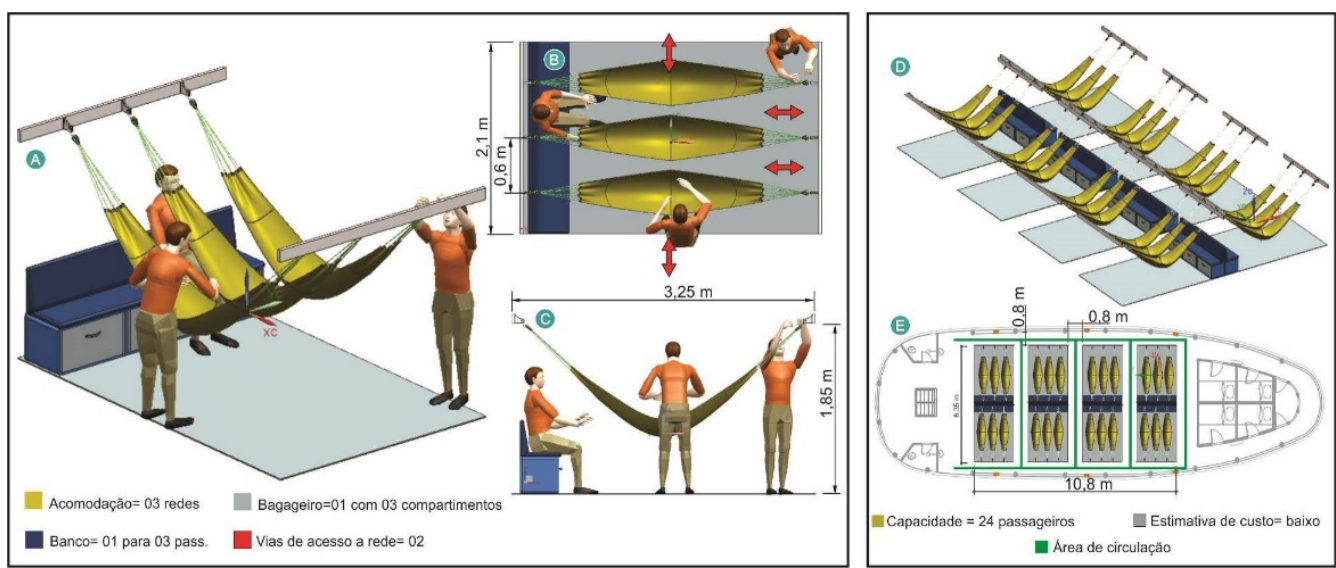

Figura 9 - Módulo (esq.); Layout proposto (dir.).

Fonte: Elaborado pelo autor, com base na pesquisa realizada.

\subsection{Avaliação da proposta}

Para selecionar a proposta condizente aos parâmetros da pesquisa, utilizou-se a técnica de avaliação binária de critérios ponderados proposta por Meister (1985) Apud Moraes e Montalvão (2003), onde foram atribuídos valores às propostas (resultado da multiplicação do coeficiente de peso pelo coeficiente de escolha). A soma dos valores mais consistentes resultou a escolha da alternativa ideal (Tabela 2).

Tabela 2 - Matriz de seleção da alternativa

\begin{tabular}{ccccccc}
\hline Critérios & \multicolumn{5}{c}{ Alternativas } \\
\cline { 2 - 7 } & $\mathbf{1}$ & $\mathbf{2}$ & $\mathbf{3}$ & $\mathbf{4}$ & $\mathbf{5}$ & $\mathbf{6}$ \\
\hline $\begin{array}{c}\text { 1-Capacidade de acomodação e espaço } \\
\text { ocupado }\end{array}$ & $\mathbf{0 , 0 8 9}$ & $\mathbf{0 , 0 7 4}$ & $\mathbf{0 , 1 0 4}$ & $\mathbf{0 , 2 0 7}$ & $\mathbf{0 , 0 1 5}$ & $\mathbf{0 , 1 7 8}$ \\
\hline 2-Acesso e circulação & $\mathbf{0 , 0 9 3}$ & $\mathbf{0 , 1 4 8}$ & $\mathbf{0 , 0 0}$ & $\mathbf{0 , 2 2 2}$ & $\mathbf{0 , 1 8 5}$ & $\mathbf{0 , 1 8 5}$ \\
\hline 3-Familiaridade & $\mathbf{0 , 0 1 5}$ & $\mathbf{0 , 0 5 9}$ & $\mathbf{0 , 0 4 5}$ & $\mathbf{0 , 0 0 7}$ & $\mathbf{0 , 0 8 2}$ & $\mathbf{0 , 1 1 1}$ \\
\hline 4-Conforto & $\mathbf{0 , 0 3 7}$ & $\mathbf{0 , 0 6 7}$ & $\mathbf{0 , 0 3 0}$ & $\mathbf{0 , 0 8 9}$ & $\mathbf{0 , 0 6 7}$ & $\mathbf{0 , 0 4 5}$ \\
\hline 5-Custo & $\mathbf{0 , 0 1 9}$ & $\mathbf{0 , 0 3 0}$ & $\mathbf{0 , 0 1 9}$ & $\mathbf{0 , 0 0}$ & $\mathbf{0 , 0 4 8}$ & $\mathbf{0 , 0 5 2}$ \\
\hline 6-Manutenção & $\mathbf{0 , 0 0 7}$ & $\mathbf{0 , 0 3 0}$ & $\mathbf{0 , 0 2 2}$ & $\mathbf{0 , 0 0 7}$ & $\mathbf{0 , 0 5 2}$ & $\mathbf{0 , 0 4 8}$ \\
\hline Resultados & $\mathbf{0 , 2 6 0}$ & $\mathbf{0 , 4 0 8}$ & $\mathbf{0 , 2 1 9}$ & $\mathbf{0 , 5 3 3}$ & $\mathbf{0 , 4 4 8}$ & $\mathbf{0 , 6 1 9}$ \\
\hline
\end{tabular}

Fonte: Elaborado pelo autor, 2014, com base na pesquisa realizada. 


\subsection{Otimização para implantação}

Para implementação da alternativa por parte dos armadores, fizeram-se algumas alterações no módulo do layout com objetivo de aumentar a capacidade de acomodação conforme pode ser visto no Quadro 4.

As alterações aumentaram a capacidade de acomodação do layout proposto, que antes era de 24 passageiros para 40 passageiros, resultando num aumento de $66 \%$ (Figura 10).

\section{Quadro 4 - Otimização da alternativa}

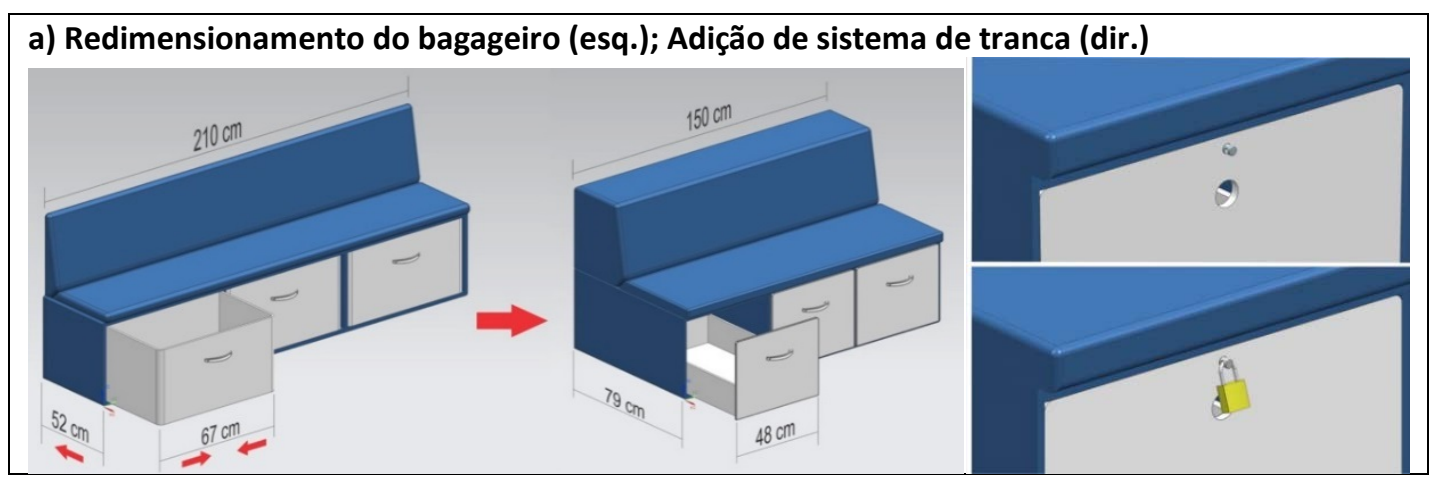

b) Redução. entre suporte das redes (esq.); Nova proposta de suporte para rede (dir.)
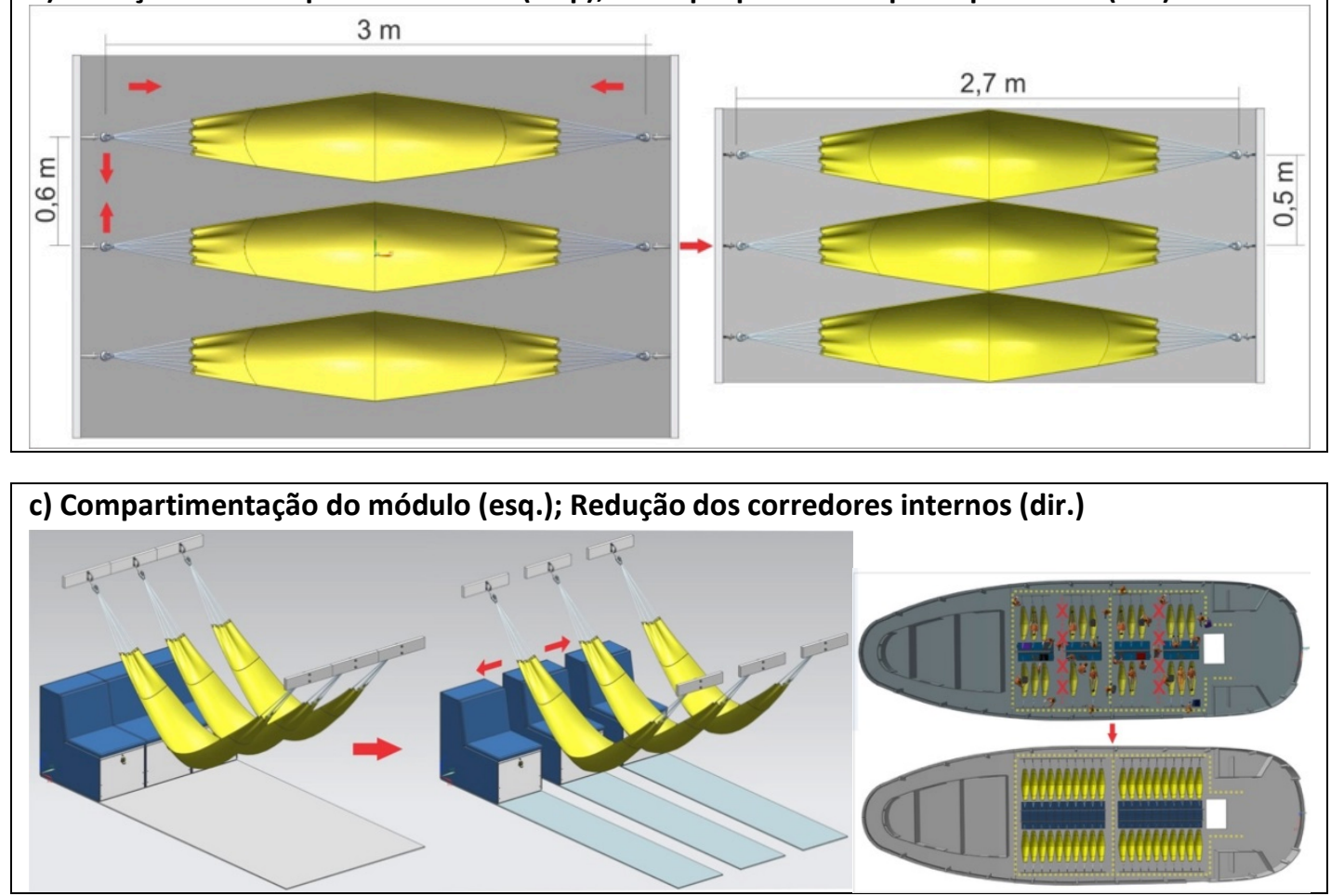

Fonte: Elaborado pelo autor, 2014, com base na pesquisa realizada. 


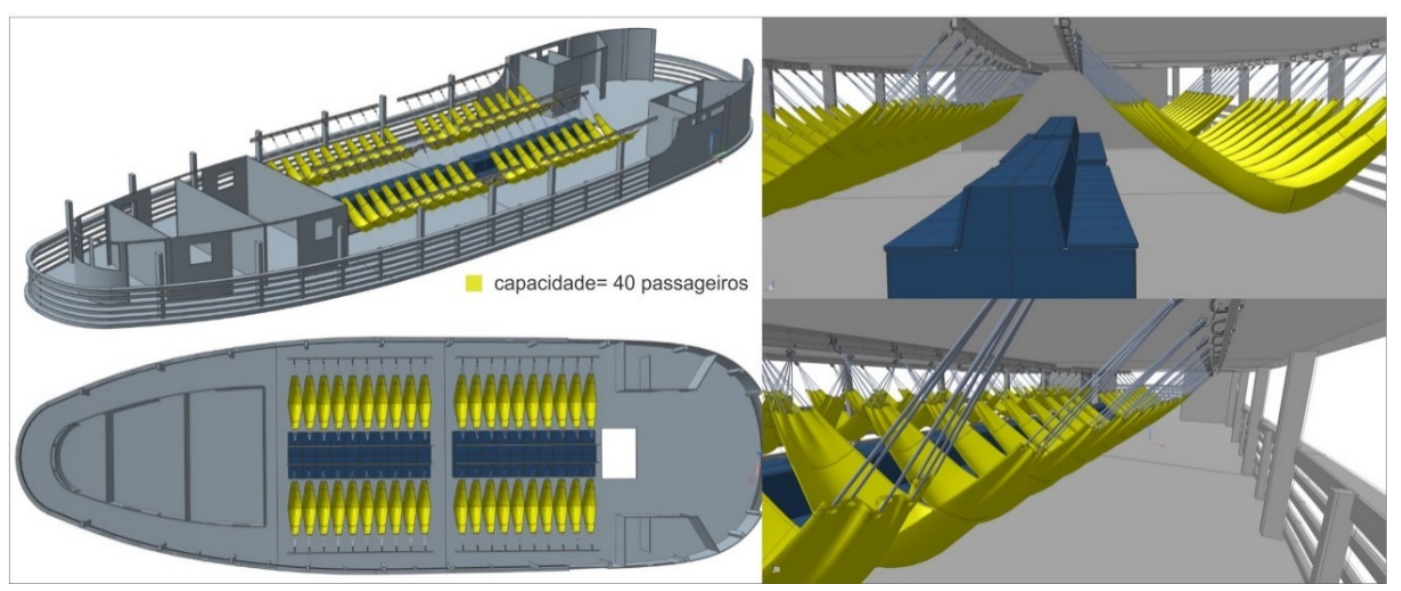

Figura 10 Layout proposto

Fonte: Elaborado pelo autor, 2014, com base na pesquisa realizada.

\subsection{Considerações finais}

Em face a realidade da acomodação dos usuários no transporte fluvial da região, esta pesquisa contribui por meio de uma proposta de layout, para melhoria significativa na qualidade do transporte fluvial da região, pois a utilização do suporte da rede e do banco/bagageiro ordenação e organiza o ambiente, melhorando a segurança do sistema uma vez que o acesso e circulação dos usuários pelo convés é facilitado.

Analisando as alternativas geradas observou-se que algumas delas possuem viabilidade de implementação caso sejam destinadas a embarcações empregadas na atividade de esporte e recreio, voltados para a região, sendo necessário à realização de futuros estudos para seu desenvolvimento.

Para que a validação da alternativa escolhida seja eficaz, sugere-se futuros estudos de implementação, por meio da construção de protótipos de um módulo, para realizar testes com usuários para obter resultados principalmente quanto a escolha de materiais previamente definidos, assim como levantamento de custo para averiguar o quanto a proposta pode afetar a tomada de decisão do armador em realizar o investimento, e quanto este impacto será repassado ao usuário do sistema.

\section{REFERÊNCIAS}

Associação Brasileira De Normas Técnicas. NBR15450: Acessibilidade de passageiros no sistema de transporte aquaviário. Rio de Janeiro: 2006. 15 p.

BAXTER, Mike. Projeto de produto: guia prático para design de novos produtos. Tradução de Itiro lida. 2. ed. São Paulo: Edgard Blucher, 2003.

BARCOPORTOALEGRE10. Portoalegre10. Disponível na internet por http: <www.barcoportoalegre10.com.br> Acesso em: Maio, 2012.

DANTAS FROTA, Cláudio et. al. Estudos de Transporte e Logística na Amazônia. Manaus: Novo Tempo, 2006. 
FANGEDB. Supercat 38 (St. Dominic). Disponível na internet por http em: <https://www.flickr.com/photos/fangedboy8/sets/72157626982764522/>. Acesso em: Maio, 2012.

HELENA MOITA, Márcia et. al. Reflexões sobre desenvolvimento, Transporte e Logística na Amazônia Brasileira. Manaus: Edua, 2011, c.12, p. 289-304.

IIDA, Itiro. Ergonomia: Projeto e Produção. 2.ed. São Paulo: Edgard Blücher, 2005. Instituto de Pesquisas Tecnológicas. Projeto de embarcações para o transporte interior de passageiros e cargas: metodologia e critérios, manual do usuário. São Paulo 1989.

L. CERVO, Amado et. al. Metodologia Científica 6 ed. São Paulo: Pearson Prentice Hall, 2007.

LEGENDTOUR. Train 010 Baikal. Disponível na internet por http em: < www.legendtour.ru/eng/train-ticket/train-010-moscow-irkutsk.shtml>. Acesso em: Maio, 2012.

MARCONI, Marina Andrade; LAKATOS, Eva Maria. Técnicas de Pesquisa: planejamento e execução e execução de pesquisas, elaboração, análise e interpretação de dados. 7. Ed. São Paulo: Atlas, 2011.

MORAES, Anamaria e MONT'ALVÃO, Cláudia. Ergonomia: conceitos e aplicações. 3 ed. Rio de Janeiro: 2AB, 2003.

MUNARI, Bruno. Das coisas nascem coisas. Tradução José Manuel Vasconcelos. 1. ed. São Paulo: Martins Fontes, 1998.

Norma da Autoridade Marítima Brasileira. NORMAM 02: Embarcações Empregadas na Navegação Interior. Porto Alegre, 2005.

PORTALNAVAL. Ferry boat Anna Nery. Disponível na internet por http em: <www.portalnaval.com.br>. Acesso em: Maio de 2012.

RUSSIANTRAIN. Train 019 Megapolis. Disponível na internet em http em:< www.russiantrain.com/info/carriage_classes>. Acesso em: Maio, 2012.

VINEYARDFASTFERRY. Ava pearl. Disponível na internet em http em:< www.vineyardfastferry.com>. Acesso em: Maio, 2012. 